\title{
A recuperação do espaço autônomo do Político o diagnóstico de uma fusão que desafia a lógica do liberalismo moderno
}

\author{
Luiz Vicente Vieira*
}

A época contemporânea manifesta um fenômeno peculiar que tem chamado a atenção de qualquer observador atento ao desenrolar dos acontecimentos políticos. A cada dia parece mais evidente as dificuldades dos governos de tomarem decisões soberanas em relação aos problemas que afligem a vida de suas respectivas nações. A visível dependência da esfera política da lógica própria que rege a economia num estágio de crescente interdependência mundial tem deixado às administrações nacionais uma margem de manobra cada vez mais restrita na busca de alternativas para resolução de seus problemas. O caminho que a sociedade liberal moderna veio a tomar ao longo de seu desenvolvimento fez com que os critérios da racionalidade econômico-

* Doutor em filosofia pela PUCRS, técnico em assuntos educacionais na UFSC. End: lvvieira@hotmail.com.br

Civitas, Porto Alegre, v. 4, nº 1, jan.-jun. 2004 
capitalista progressivamente viesse a substituir os critérios políticos na condução da existência das comunidades modernas, fazendo com que os cálculos econômicos passassem a constituir-se nos princípios fundamentais do agir político. A conseqüência inevitável deste fato seria indubitavelmente a ausência de um espaço autônomo do Político no interior da comunidade moderna. Refletir as razões e os desdobramentos deste fenômeno constitui-se, então, no foco central desta reflexão.

Para a abordagem desta questão, no entanto, ao invés de estabelecer uma crítica externa aos pressupostos teóricos que historicamente vieram a legitimar este novo papel que a idéia do Político passou a assumir na sociedade contemporânea, julgo de maior valor analítico a via por uma adequada compreensão da lógica interna que move a conceitualização política liberal e que busca justificar a atual ordem social econômica e política. Ou seja, no lugar de contrapor à teoria do liberalismo uma visão oposta a esta, como forma de pensar as condições necessárias para a recuperação da autonomia do espaço do Político, pretendo mergulhar nos princípios subjacentes à teoria liberal, procurando avaliar em que medida os seus pressupostos conseguem dar coesão ao funcionamento da sociedade liberal, mediante a compreensão da "sistematicidade entrelaçadora" (Flickinger, 2003) entre os vários níveis que a compõem no seu todo.

É por este motivo, portanto, que penso que uma tal abordagem deveria ter como ponto de partida a reconstrução de alguns momentos privilegiados da formação do pensamento liberal, destacando como certos conceitos da Filosofia Política são reinterpretados por esta corrente teórica. À medida todavia, que penetramos na cadeia argumentativa que visa legitimar os conceitos inerentes à vertente liberal, paulatinamente torna-se evidente um impulso abstraidor que parece mover o processo de elaboração de seus conceitos. Este impulso revela-se tanto na tendência inerente às suas noções jurídico-políticas de abstraírem-se continuamente das questões materiais do horizonte de suas aplicações, quanto na conseqüente abstração do caráter de "vontade" e decisão das instâncias do poder, que passam a submeter-se ao estrito cumprimento de normas procedimentais, o que inegavelmente entrava ou deixa impotente a ação estatal. Estes são os pressupostos que haverão de modelar a idéia do moderno estado de direito, onde tal dinâmica abstraidora manifesta-se através deste conceito de estado restrito à simples formalidade ou legalidade do agir. De outra parte, concomitantemente à figura do estado liberal de direito, o sistema representativo moderno irá assumir o papel de justificação do poder que, a partir de agora, diferentemente do período absolutista, deverá encontrar a sua legitimidade na escolha popular dos governantes, modelo este que passará então a ser denominado de democracia representativa de massas ou democracia liberal. Um outro traço marcante ainda 
percebido ao longo do desenvolvimento da doutrina liberal é sua inegável capacidade de reatualizar-se conforme as várias fases da história moderna, sempre numa íntima relação com os desdobramentos da forma predominante de reprodução social da modernidade, tendo, por este motivo, de experimentar permanentemente novos testes que a realidade social e política de cada época apresenta. Desde sua fase inaugural, através do estabelecimento de seus primeiros preceitos com John Locke, passando pela teoria da divisão dos poderes de Montesquieu, quanto à formulação do Estado Jurídico por Immanuel Kant, e ainda posteriormente com os chamados liberais clássicos como Benjamin Constant e J. S. Mill, o liberalismo demonstrou esta capacidade de adaptação à cada nova circunstância histórica. Processo este que há de culminar no século XX de um lado, nas correntes do positivismo jurídico, através do pensamento de Hans Kelsen, e, de outro, na corrente do neoliberalismo, como mediante as posições de Friedrich Hayek, autores estes que polemizaram quanto ao significado e ao papel do estado liberal de direito no contexto da comunidade liberal contemporânea. É esta sua capacidade que tem permitido ao liberalismo apresentar-se até o momento razoavelmente sustentável.

No entanto, alguns autores de certa maneira vinculados à tradição liberal, como Norberto Bobbio e Hermann Heller (1998) não deixaram de apontar alguns problemas teóricos inerentes à estrutura e à organização do estado de direito. A este propósito Hermann Heller aponta que a conformidade de um ato estatal com a lei e desta com a constituição juridico-política só poderia constituir a base de uma legalidade, mas jamais de uma legitimidade justificadora. Assim, ainda conforme este autor, se a organização democrática do estado de direito, com sua divisão de poderes e direitos fundamentais, tornou-se num mecanismo eficaz para limitar a arbitrariedade e a utilização abusiva do poder político pelos dirigentes - pois na idade média, por exemplo, não existia uma clara oposição entre direito subjetivo e objetivo e entre direito público e privado-, todavia aponta ele para a impossibilidade da tese da redução da legitimidade pela legalidade. Porque, acrescenta, além de seu mecanismo funcional, que representa um inegável avanço em relação ao ideal da modernidade de liberdade para todos, entretanto, o estado de direito será sempre dependente de um determinado conteúdo material. Em outros termos, a mera idéia do estado de direito, haverá de servir não só àqueles princípios jurídico-formais, mas sempre descansa sobre certos valores e conteúdos que são historicamente determinados pelas forças políticas que alcançam o poder do estado e que têm a sua disposição a ordem jurídica estabelecida por órgão estatais (cf. Heller, 1998, p. 264).

Tais ponderações já nos apontam para possíveis ambigüidades ou contradições que encerram o conceito de estado de direito. Entretanto, uma 
análise mais profunda desta tensão inerente à forma como foi concebida a noção de estado de direito será desenvolvida pelo politólogo alemão Carl Schmitt (1982), tema este que constitui o segundo ponto desta reflexão. Schmitt, no intuito de desenvolver sua crítica aos princípios liberais que fundamentam a idéia do estado de direito, recorrerá a uma tradição que encontra em Rousseau uma formulação da política e do estado. Numa época onde a corrente liberal ainda não se encontrava perfeitamente delineada, Rousseau já manifestara certas reservas a seus pressupostos, colocando-se assim, de alguma maneira, na contramão do liberalismo. A crítica contundente de Rousseau à concepção do sistema representativo através da instituição dos deputados enquanto delegados da soberania popular bem como a sua reserva incontinente à subordinação da política à economia caracterizam claramente a desconformidade do autor com alguns preceitos fundamentais da doutrina liberal. Já Carl Schmitt, que conviveu com os problemas do estado numa época em que esta doutrina encontrava-se plenamente desenvolvida, haverá de concentrar-se na diagnose dos problemas decorrentes das estruturas de poder do estado liberal de direito, preocupando-se sobremaneira com o caráter contratual que o mesmo passara a assumir, especificamente no período da República de Weimar, a qual, segundo ele, era alvo da investida de interesses privados. E, ao chamar a atenção para a crescente privatização do espaço público-estatal, mediante a subordinação do poder político à racionalidade econômica, passa a debruçar-se sobre as contradições que ele detectava ao nível de princípios, tanto da idéia de estado de direito, quanto do parlamentarismo como modelo político de legitimação do poder.

A grande diferença entre a tradição liberal e aquela a que se vinculam Rousseau e Carl Schmitt consistirá, portanto, no fato de que enquanto a corrente liberal admite uma base contratual para a fundamentação do estado, a partir de uma igualdade formal ou jurídica e onde o parlamento constitui-se no espaço de negociação entre diferentes interesses que coexistem no seio da sociedade civil, Rousseau e Schmitt reivindicam uma homogeneidade que vá além de seu caráter meramente jurídico. Ou seja, uma homogeneidade substancial. Porque, caso contrário, segundo esta vertente, o estado ficaria permanentemente cativo das disputas e dos interesses hegemônicos da sociedade civil. Em termos rousseaunianos, o poder do estado encontrar-se-ia, dirigido pela vontade de todos e não pela Vontade Geral. O que não se constituiria numa base sólida para a ação do estado, e que poderia vir inclusive a comprometer a própria sobrevivência do corpo político, na linguagem de Rousseau, ou da unidade política, na expressão de Schmitt.

No entanto, ao longo do resgate dos posicionamentos da tradição a que se ligam estes dois autores, é imprescindível destacarmos algumas diferenças de pontos de vista entre ambos. Porque, ao contrastarmos alguns de seus 
diagnósticos e posicionamentos com referência a determinadas questões, fica evidente a não coincidência parcial ou total em relação às mesmas. Exemplo disto é a exigência partilhada por ambos de que a homogeneidade como base do estado, ultrapasse o seu mero caráter jurídico-formal. Entretanto, o mesmo não ocorre quando comparamos o sentido que cada um atribui a esta homogeneidade, onde então é nitidamente perceptível aí uma clara dissonância não só entre os conteúdos concretos que atribuem respectivamente a este conceito, como na forma de atingir-se esta homogeneidade. Tais diferenças entre as perspectivas destes autores terão, aliás, consequiências inevitáveis nas sugestões e soluções que cada um deles oferecerá como alternativas à visão liberal do estado.

Se, todavia, a advertência de Carl Schmitt, apresentada na sua Teoria da Constituição, de 1928, de que o estado de direito carrega uma ambigüidade mediante a qual a sua existência depende de permanentemente evitar o elemento político inerente a qualquer forma de estado, para que o elemento político jamais viesse a manifestar-se, então será que tais ambigüidades ou contradições poderiam explicar, ao menos em certa medida, a atual crise de legitimidade do estado liberal de direito e de seus canais legais de representação? A terceira e última etapa desta abordagem deveria, ao meu ver, visar responder a esta questão mediante o esforço de procurar diagnosticar o fenômeno da crise de legitimidade do moderno estado de direito junto a parcelas significativas da população. E, para este objetivo, a reconstrução dos aspectos históricos que conduziriam a esta crise constituem-se num procedimento indispensável para a configuração da mesma. Antes, contudo, de considerarmos os seus desdobramentos torna-se necessário levantar um elemento indispensável na apreciação dos impasses que o estado de direito passa a enfrentar nos dias atuais. Pois se a conexão estabelecida por este conceito de estado entre legalidade e legitimidade, como foi indicado anteriormente, consegue até certo ponto apresentar-se como um remédio contra a arbitrariedade e o uso abusivo do poder pelos seus titulares, na contrapartida, porém, a restrição da ação do estado à mera formalidade do agir e à própria dependência do Estado da lógica imanente da Economia, tem permitido o crescimento incontrolável das desigualdades, o qual resulta num incontido processo de exclusão social. A partir desta observação é que se atinge a problemática que encerra a restrição da idéia do estado de direito enquanto simples caráter técnico-formal, sem referência a valores substanciais. Uma vez que o mesmo torna-se impotente e incapaz para realizar uma mínima justiça material que pudesse conduzir à solução de suas crises recorrentes.

A idéia do estado de bem-estar social, que foi ensaiada como possível solução para os problemas de legitimação do estado contemporâneo, parece fadada ao insucesso devido à crise fiscal resultante das dificuldades da 
manutenção de um crescimento econômico continuado, colocando assim em risco a eficácia de suas políticas corretoras das disfunções do mercado. O problema é que o estado do bem-estar constitui-se na contraface do estado de direito e, por isso mesmo, encontra-se igualmente submetido à restrita submissão à legalidade do agir, logrando tão somente reconhecer direitos sem necessariamente poder realizá-los. O resultado é, por conseguinte, o decorrente déficit de legitimidade de seus próprios canais legais de representação reconhecidos pelo estado de direito como os sindicatos e partidos políticos. Fenômeno este que pode nos ajudar a explicar por que a marginalização e exclusão social têm jogado na cena política os denominados novos movimentos sociais, cujas demandas sequer são contempladas no plano econômico pelos sindicatos, inclusive por conta do aumento do desemprego, assim como o sistema de partidos competitivos não consegue canalizar quantitativa e qualitativamente os reclames de parcelas expressivas da sociedade. Estes movimentos manifestam então práticas políticas avessas aos procedimentos institucionalizados, sem se acharem obrigados por isso a respeitar as regras do jogo institucional, criando-se, assim, uma permanente tensão social que cresce à medida que fica mais distante tanto a realização de uma justiça material, quanto o reconhecimento de reivindicações de nível social, cultural e política não contempladas pelas estruturas de poder do estado liberal de direito.

Tudo indica, portanto, que as diagnoses de Carl Schmitt tornam-se produtivas para detectarmos algumas contradições chaves que podem certamente explicar as crises recorrentes do estado de direito. Contudo, será que suas receitas nos ofereceriam uma alternativa aceitável aos impasses que o mesmo vem enfrentando?

Nesta altura de nossa abordagem é possível constatarmos a nítida oposição entre as posições do liberalismo e a de Carl Schmitt com referência à relação entre a sociedade e o estado. Porque, de uma parte, a corrente liberal vê esta relação unilateralmente do ponto de vista da sociedade civil, demonstrando uma desconfiança para com o estado ao buscar subordiná-lo a sua dinâmica interna: quer das leis imanentes que regem o âmbito da produção material, quer do direito liberal que visa garantir as condições de sua reprodução, deixando, deste modo, o estado dependente tanto da racionalidade econômico-capitalista quanto da restrita legalidade do agir, procurando, assim controlá-lo de qualquer maneira e tornando-o impotente pela ausência no seu seio de um espaço autônomo de decisão. É evidente que tal postura resultará inevitavelmente nas conseqüências avassaladoras decorrentes de sua incapacidade de conter o crescimento das desigualdades e pondo em risco, por este motivo, a própria sobrevivência da idéia do estado de direito. Já Carl Schmitt, de outra parte, colocando-se do ponto de vista do estado, manifesta a sua reserva com referência à sociedade civil dominada, segundo ele, pelo pluralismo excessivo 
dos chamados complexos sociais de poder (Cf. Schmitt, 1986), os quais colocariam em perigo a unidade e a segurança do estado. E, com o intuito de eliminar os efeitos prejudiciais deste pluralismo nocivo, ele julga que o estado deveria impor-se de qualquer modo sobre a sociedade civil.

Colocadas as coisas nestes termos, parece não haver saída para tal impasse, a não ser a opção unilateral por algum destes pontos de vista. Entretanto ambas soluções resultam em consequiências inevitáveis no contexto da comunidade moderna. E, por conseguinte, não se trata de exorcizar o pluralismo do mundo social, uma vez que, como pondera Hegel, ele representa menos uma ameaça para a vida ética que um de seus elementos constitutivos. De outra parte, o pluralismo social não oferece uma base segura para o estado, já que o reduziria a uma base contratual. Daí o porquê de Hegel postular a tese da mediação recíproca do social pelo político e do político pelo social. Pois, como observa no parágrafo 256 da Filosofia do Direito, o estado moderno é o verdadeiro fundamento da sociedade civil, da mesma forma que estado de direito não existe sem a sociedade civil, sublinhando o autor, desta maneira, a natureza simultaneamente distinta e indissociável entre estado e sociedade civil. Neste sentido poderíamos ratificar a expressão J. F. Kervégan de que "a intervenção do estado na sociedade civil não se constitui em uma perturbação indevida numa ordem espontânea, como pretende a ortodoxia liberal, nem a beneficência de uma perigosa desordem por um terceiro superior, como sugere Schmitt" (Kervégan, 1992, p. 236).

Se, no entanto, no que tange a esta questão da relação entre estado e sociedade civil, a posição de Carl Schmitt mereceria ser ponderada e revista, o mesmo não se pode dizer com referência a Rousseau. Pois a necessidade da mediação como traço característico do estado moderno encontra-se no horizonte de suas preocupações. Esta perspectiva é claramente apontada no capítulo III do livro 2 do Contrato social, onde o autor buscou precaver-se contra a degeneração da base legitimadora do estado ao denunciar o perigo das sociedades parciais, como obstáculo para se alcançar a vontade geral; entretanto, ao constatar a impossibilidade ou a dificuldade de evitá-las (como que intuindo a nova realidade resultante da emergência da sociedade civil), propôs a multiplicação destas associações, não só como forma de neutralizar os grupos mais poderosos, quanto também para permitir a possibilidade de que todos se manifestassem e desta maneira, segundo suas próprias palavras, "impedir-lhes a desigualdade". Quanto a este ponto, como bem assinalou ainda Kervégan, Hegel, "o monarquista, e Rousseau, o democrata, encontram-se para colocar a questão do estado em termos de mediação" (Kervégan, 1992, p. 100).

A posição de Rousseau, portanto, em relação a esta questão, ao admitir a mediação entre a variedade e multiplicidade de interesses existentes na 
sociedade como condição de atingir-se a vontade geral, abre incontestavelmente a oportunidade, hoje, para os diversos movimentos sociais não só de manifestarem suas reivindicações e demandas, quanto de incorporálas no esforço coletivo de construção de uma base comum para dirigir "as forças do estado", o que lhes permitiria ascender à condição de exercerem uma função política, passando, assim, a assumirem uma relevância no espaço político. O problema é que os novos movimentos sociais têm sido apenas interpretados como elementos nascidos dentro da própria sociedade civil enquanto espaço onde se manifestam os interesses particulares, a pluralidade de visões e projetos sociais. Qual, todavia, a qualidade capaz de elevá-los do nível da sociedade civil para o do âmbito do político? Em termos rousseaunianos, poderíamos afirmar que eles se apresentariam como momentos da constituição de uma vontade geral. Mas não, certamente, como os momentos únicos deste processo, porém integrando este espaço com elementos do sistema liberal, como o multipartidarismo, o que poderia corresponder a um aperfeiçoamento deste sistema. Pois, na concepção liberal do estado a representação é exclusivamente individual e, neste caso, tratar-se-ia de uma transformação de seus mecanismos representativos ao incluir-se formas de representação não individuais reconhecidas pelo estado de direito na sua estrutura jurídico legal.

A análise das estruturas do estado liberal de direito revela-nos, portanto, uma tensão, inerente ao seu mecanismo de funcionamento, que se reflete nas conseqüências de sua abstração material em termos do seu agir político. Pois o Político pode ser tanto identificado com a esfera da eticidade, onde ocorreria a legitimação substancial de posições, da mesma forma que pode ser reduzido à mera legalidade do procedimento. Neste último caso, a legalidade torna-se inevitavelmente o único critério da legitimidade. O que, como já assinalei, apresenta-se como um problema para os movimentos sociais por não serem os mesmos reconhecidos enquanto portadores de uma função política objetiva, mas que, todavia, independente dos interesses e demandas particulares que eles representam, perseguem continuamente esta intenção, qual seja, de se tornarem fatores de articulação ao que ainda não foi dado voz em nível político.

A conclusão final a que pretende chegar este trabalho, portanto, é que a partir da perspectiva aqui desenvolvida, é procedente admitir-se que o liberalismo, enquanto doutrina que fundamenta a estruturação do nível político da sociedade moderna, só poderia continuar sendo defensável como sistema capaz de agüentar esta processualidade que tende a questioná-lo enquanto um modelo uma vez dado e não mais reatualizado. Na medida que ele consegue resistir a esta processualidade é que poderia ser sustentável, mas somente nestas condições. Pois, a processualidade da realidade política contemporânea expõe a estrutura da legalidade a testes permanentes quanto a sua capacidade de respeitar a diversidade nas suas estruturas de poder. Os novos movimentos 
sociais constituem-se hoje nestes testes, ao exigir a reconsideração permanente da legalidade, a qual deixe de corresponder simetricamente a uma contínua linearidade do processo de exclusão social. E, sob este ponto de vista, eles criam a possibilidade da sociedade moderna voltar enfim a refletir sobre a necessidade do retorno de um espaço autônomo do Político.

\section{Referências}

FLICKINGER, H.-G. A lógica imanente do liberalismo político. Pelotas: Educat, 1998. A lógica imanente do liberalismo moderno. In: ——. Em nome da liberdade. Porto Alegre: Edipucrs, 2003.

HELLER, H. Teoria del estado. México: Fondo de Cultura Económica, 1998.

HEGEL, G. W. F. Princípios de la Filosofia del Derecho. Barcelona: Edhasa,1988. KERVÉGAN, J. F. Hegel, Carl Schmitt: la politique entre spéculation et positivité. Paris: PUF, 1992.

A democracia inatual? Filosofia Política, Porto Alegre, nº 3, 1986.

ROUSSEAU, J. J. Ouvres completes. Paris: Pléiade Gallimard,1964.

. Coleção Os Pensadores. São Paulo: Abril Cultural, 1978.

SCHMITT, Carl. O conceito do Político. Petrópolis: Vozes, 1992.

- Teoria de la Constitución. Madri: Alianza Editorial, 1982.

—. La defensa de la Constituçión. Madrid: Tecnos, 1983.

Texto recebido em 18.11.03 e aprovado em 30.03.04 